\title{
Reexamining Student-Athlete GPA: Traditional vs. Athletic Variables
}

\author{
James E. Johnson, Roger D. Wessel, and David Pierce \\ Ball State University
}

\begin{abstract}
A sample of 674 first-year student-athletes at a midsize Midwestern university were examined each year over a five-year period (2004-2008) to determine if athletic variables were powerful enough to be used in conjunction with traditional predictors of college success to predict GPA. The four specific athletic variables unique to student-athletes (i.e., sport, coaching change, playing time, team winning percentage), were hypothesized to be as predictive as traditional variables. Pearson correlations revealed student-athletes were more likely to earn a high first-year GPA if they were female $(r=.35)$, Caucasian $(r=-.33)$, scored well on standardized tests $(r=-.47)$, had a respectable high school GPA $(r=.64)$, were ranked high in their graduating high school class $(r=-.58)$, had a relatively large high school graduating class $(r=.15)$ were not undecided about major $(r=-.11)$, were not a member of a revenue sport $(r=.33)$, and earned a considerable amount of playing time in their first year $(r=-.15)$. Least squares linear regression demonstrated the traditional variables of gender $(B=.16)$, race $(B=-.26)$, standardized test scores $(B=.03)$, high school GPA $(B=.41)$, high school rank $(B<-.01)$, and size of high school graduating class $(B<.01)$ were most influential in predicting first-year student-athlete GPA.
\end{abstract}

On August 1, 1986 the National Collegiate Athletic Association (NCAA) enacted legislation known as Proposal 48. This legislation mandated graduating high school seniors must score a combined 700 on the Scholastic Aptitude Test (SAT) or a 15 on the American College Testing (ACT) test, and have a minimum high school GPA of 2.0 to be eligible for college athletic competition (Baumann \& Henschen, 1986). Prop 48, as it is now referred, set off a wave of research investigating the minimum test scores and GPA requirements to determine if the cut-off points were appropriate. Since the mid 1980s, research on student-athlete GPA has identified several variables closely related to GPA. However, in the continually changing world of college athletics, where eligibility and penalties are still tied to academic performance, it is a worthwhile undertaking to continually revisit the traditional predictors of GPA. It is also prudent to explore new variables that are unique to college student-athletes.

Although exploration of traditional and athletic variables was reason enough to validate this study, there is another pressing issue facing college student-athletes

Johnson is with Academic Support Services; Wessel is with the Department of Educational Studies; and Pierce is with the School of Physical Education, Ball State University, Muncie, IN. 
which makes continued GPA research particularly timely. Enacted in 2005, the Academic Progress Rate (APR) is part of the most recent academic reform package by the National Collegiate Athletic Association (NCAA). Similar to Proposal 48 , the APR is groundbreaking legislation that has wide-ranging impact, but is only now producing useful longitudinal information. Unlike previous eligibility markers, which focused primarily on individual eligibility or delayed graduation rates, the APR provides a semester-by-semester look at the academic culture for each athletic team. The APR also offers a national comparison for different sports, conferences, and institutions based on team APR scores. During a semester a student can earn two points. One point is earned for being academically eligible, and one is earned for returning to school the following semester (i.e., retention). An eligibility point is earned when an individual is certified eligible through an institution's compliance department by meeting the GPA, credit hour, and progress toward degree minimum standards. Individual points are then used to calculate a team score. Historically low team scores could trigger a variety of penalties from the NCAA (Brown, 2005). Because APR scores include GPA as a primary determinate of scoring, and individual eligibility is in part determined by GPA, it is logical to conclude coaches and athletic administrators would have a vested interest in determining what types of variables best predict GPA, and if variables unique to student-athletes significantly aid in that determination.

In addition to eligibility and APR scores, GPA can influence other areas of a student-athlete's life. Scholarships and financial aid often have GPA requirements. Coaches may use high school GPA to evaluate recruits, or they may use college GPA of a current player to make judgments about dedication to academics or individual awards. In addition, transfer students must meet minimum GPA requirements to be eligible. Furthermore, GPA cut-off scores may determine who, and what types of academic support services are available to particular student-athletes. These uses for GPA, combined with eligibility and APR scores, demonstrate the wide-ranging impact GPA has on student-athletes. Therefore, identifying which variables impact GPA is important to coaches and athletic administrators.

Determining what qualifies as traditional variables is a difficult task. Certainly there are some variables used most often by college admission departments and coaches during the recruiting and admissions process. These variables have been widely researched and generally understood to be related with college academic performance. Three of the most traditional variables are demographic in nature (i.e., gender, race, and distance from home), and have been consistently associated with college GPA. Specifically, females tend to outperform males in nearly every academic measure (Betz \& Fitzgerald, 1987; Kane, Leo, \& Holleran, 2008; Mayo, 1982; Purdy, Eitzen \& Hufnagel, 1982; Rosser, 1989), and Caucasians tend to have higher academic achievement than other races (Babington, 1997; Chee, Pino, \& Smith, 2005; Killeya, 2001; Sedlacek \& Adams-Gaston, 1992; Sellers, 1992; Walter, Smith, Hoey, Wilhelm, \& Miller, 1987). Distance from home is a variable that can logically be linked to college performance due to the many personal and social relationships formed during high school. According to Fisher (1989), "the greater the distance incurred the greater the likelihood of change in culture-hence the greater the likelihood of culture shock" (p. 72). This idea is reinforced by research indicating distance from home is an important factor in college choice (Briggs, 2006; Cunningham, 1997; Higher Education Research Institute, 2008). 
In addition to gender, race, and distance from home, several academic variables have traditionally been linked to college GPA. Those variables include standardized tests, being undecided about a major, high school GPA, high school rank, and high school size. The two most common standardized tests accepted for college admissions are the SAT and the ACT. Although standardized tests have been the subject of much criticism (Hoffman, 1961; Worthen \& Spandel, 1991; Young \& Kobrin, 2001; Zwick, 1999), they continue to be widely used by college admissions departments, and have generally been found to be a valuable indicator of college success if used in conjunction with high school measures of achievement (Baker \& Siryk, 1989; Baumann \& Henschen, 1986; Burton \& Ramist, 2001). Being undecided about a major, however, is a traditional variable that warrants more evaluation within the world of college athletics. On one hand, students who commit to a major are thought to be more committed students with clearer goals and objectives than students who are undecided (Cooney, 2000; Ridener, 1999; St. John, Hu, Simmons, Carter, \& Weber, 2004). On the other hand, Kroc, Howard, Hull and Woodard (1997) and Knight (1994) found graduation rates were not significantly different for undecided students.

High school GPA is the most logical variable used by college admissions departments because it is a clear indicator of previous academic performance. For student-athletes, high school GPA has been found to be one of the most powerful predictors of college success (Allen, 1986; Baumann \& Henschen, 1986; Lang, Dunham \& Alpert, 1988; Sellers, 1992). High school rank, which is a studentspecific measure relative to performance of other students, has also been a traditionally strong indicator of college success (Cohn, Cohn, Balch \& Bradley, 2004; Ruban \& Nora, 2002; Schwartz \& Wilber, 1981). High school size is commonly used with high school GPA and rank to contextualize the academic environment of the student. Predicated on the logic that larger high schools will have more academic resources and opportunities, researchers have found class size to be a traditional predictor of academic success (Ashbaugh \& Thompson, 1993; Geffert \& Christensen, 1998; McDaniel \& Graham, 1999).

Beyond these traditional variables, there are athletic variables unique to student-athletes. These athletic variables are important to investigate because they account for a large portion of the college experience within this student sub group. The type of sport team on which a student-athlete participates has been linked to both GPA and graduation rates. Specifically, the revenue sports of football and men's basketball have continually demonstrated the lowest academic achievement and graduation rates of all sports (NCAA Research Staff, 2008). In addition, APR scores are lowest for revenue-producing sports (Academic Progress Rate, 2009; NCAA Research Staff, 2009). The second athletic variable, coaching change, is a logical choice as a potential influence on GPA. Given the vast amount of interaction and oversight a college coach provides (Field, 1991; Giacobbi, Roper, Whitney, \& Butryn, 2002), it is reasonable to conclude that student-athletes who experience a coaching change during their first year may be negatively impacted.

Playing time is the third nontraditional athletic variable that has the potential to impact GPA. High school athletes who are good enough to play in college did not have to worry about their high school participation. They were likely the best players on their team. This level of skill creates an identity heavily dependent on athletic status (Melendez, 2006), and produces athletes that are more prepared 
emotionally and physically (Kauss, 1978). Furthermore, athletes with high levels of playing time have higher mastery goal orientations, higher perceptions of their abilities, and higher levels of satisfaction (Petlichkoff, 1993a, 1993b). It is unclear whether playing time has the same type of effect on student-athlete GPA.

Finally, team winning percentage is a uniquely athletic variable that may impact GPA. If the old cliché is true, and there is no I in team, then it can be assumed studentathletes may be more impacted by team performance than their individual playing time. Previous research is limited on the effects of team performance on GPA, but it is clear the winningest revenue sport teams perform at the lowest levels (Institute for Diversity and Ethics in Sport, 2008; Institute for Diversity and Ethics in Sport, 2009), while other more academic institutions see little evidence of a link between winning games and academic success (Akker, 1995; Kotlyarenko \& Ehrenberg, 2000). This study attempted to determine if winning percentage, as well as the other athletic and traditional variables, has a significant relationship with student-athlete GPA.

\section{Method}

Six-hundred-seventy-four first-year student-athletes were sampled during a five year span from 2004 to 2008. Each student was sampled once during their firstyear of college. The sample was taken from the population of all student-athletes at a midsize Midwestern doctoral university (approximately 20,000 students) with 19 NCAA Division I athletic programs. Participants were evaluated using eight traditional variables used to predict college GPA (i.e., gender, race, distance from home, major, standardized test scores, high school GPA, high school rank, and size of high school graduating class), and four athletic variables (i.e., sport, coaching change, playing time, and team winning percentage). All variables were hypothesized to be significant predictors of retention.

Identifying a comprehensive list of student-athletes was achieved by utilizing records from the Office of Academic Support Services for Student-Athletes. This office compiles specific academic information regarding team rosters from all coaches before the beginning of the academic year, and acts as the liaison between the Athletic Department and academic departments. Approval was granted by both the Coordinator of Academic Support Services, and the Institutional Review Board before data collection occurred.

After the list of student-athletes was created, information about gender, race, distance from home, standardized test scores, high school information, and major was gathered from the university's central informational database. The information about sport, coaching change, playing time, and team winning percentage were collected using the university athletics website and athletic media guides. The data included all of the relevant student-athlete information for each incoming class of student-athletes during the five years investigated in this study (2004-2008). For clarity during data collection, the operational definitions of all variables were required (see Figure 1).

To ensure no individual participants were identifiable by the raw data, information was grouped by the variables under investigation, and analyzed as one data set for the entire five-year time period. No individual years were identified in the analysis or evaluation of the data. Collapsing the data into one data set covering a five-year period ensured no student-athlete was recognizable by the year they entered school. 
Figure 1 - Summary of variables with explanations of categories

\begin{tabular}{|c|c|}
\hline $\begin{array}{l}\text { Traditional } \\
\text { Variables }\end{array}$ & Category Definitions \\
\hline Gender & $\begin{array}{l}\text {-Male } \\
\text {-Female }\end{array}$ \\
\hline Race & $\begin{array}{l}\text {-Race } 1 \text { = Caucasian compared with African American } \\
\text {-Race } 2 \text { = Caucasian compared with all other minority races except } \\
\text { African Americans }\end{array}$ \\
\hline $\begin{array}{l}\text { Distance } \\
\text { From Home }\end{array}$ & $\begin{array}{l}\text {-Short }=\text { home is less than } 100 \text { miles from the university } \\
\text {-Medium = home is } 101-250 \text { miles from the university } \\
\text {-Long = home is more than } 250 \text { miles from the university }\end{array}$ \\
\hline Major & $\begin{array}{l}\text {-Had major }=\text { identified major upon entrance into university } \\
\text {-Undecided }=\text { declared no major upon entrance into the university }\end{array}$ \\
\hline $\begin{array}{l}\text { Standardized } \\
\text { Test Scores }\end{array}$ & $\begin{array}{l}\text { ACT composite score, or SAT total score converted into ACT score } \\
\text { format using a concordance table provided by American College Test- } \\
\text { ing services. If a student had both scores, ACT composite was used. }\end{array}$ \\
\hline $\begin{array}{l}\text { High School } \\
\text { GPA }\end{array}$ & $\begin{array}{l}\text { Grade point average of core high school courses. Core courses include } \\
\text { math (e.g., algebra, geometry, calculus, etc.), science (e.g., biology, } \\
\text { chemistry, Earth science, etc.), social studies (e.g., history, psychol- } \\
\text { ogy, sociology, etc.), English, and foreign language. }\end{array}$ \\
\hline $\begin{array}{l}\text { High School } \\
\text { Rank }\end{array}$ & $\begin{array}{l}\text { Number assigned to students resulting in a ranking relative to others } \\
\text { in their high school class (usually based on GPA). }\end{array}$ \\
\hline $\begin{array}{l}\text { High School } \\
\text { Size }\end{array}$ & $\begin{array}{l}\text {-Small = less than } 150 \text { students in graduating class } \\
\text {-Medium }=150-300 \text { students in graduating class } \\
\text {-Large }=\text { more than } 300 \text { students in graduating class }\end{array}$ \\
\hline $\begin{array}{l}\text { Athletic } \\
\text { Variables }\end{array}$ & Category Definitions \\
\hline Sport & $\begin{array}{l}\text {-Revenue sport = football, men's basketball, women's basketball } \\
\text {-Nonrevenue sport = all other sports ( } 16 \text { total) }\end{array}$ \\
\hline $\begin{array}{l}\text { Coaching } \\
\text { Change }\end{array}$ & $\begin{array}{l}\text {-Change = change in the head coach during the first year of a student- } \\
\text { athlete's college education. } \\
\text {-No change = head coach was the same the entire first year }\end{array}$ \\
\hline Playing Time & $\begin{array}{l}\text {-Low }=\text { played in less than one third of total contests* } \\
\text {-Medium = played in one third to two thirds of total contests* } \\
\text {-High = played in more than two thirds of total contests* }\end{array}$ \\
\hline $\begin{array}{l}\text { Winning } \\
\text { Percentage }\end{array}$ & $\begin{array}{l}\text { The number of wins divided by the number of total contests for a } \\
\text { sport season (any ties were eliminated from the calculation). For } \\
\text { men's and women's golf, and women's track, winning percentage was } \\
\text { defined as the mean percentile ranking of all multiteam competitions. }\end{array}$ \\
\hline
\end{tabular}

* men's and women's basketball were evaluated by dividing their season into thirds based on minutes, not games. 
Data sets were statistically analyzed only after the data were collected, collapsed into one data set, and names/identification numbers were deleted. Upon completion of the data collection, the data were analyzed using Predictive Analytics Software version 18. Analysis included frequencies and measures of central tendency for descriptive purposes. Independent predictor variables were then subjected to Pearson correlations and least squares logistic regression against the dependent variable of GPA at the end of the first academic year (not including summer school).

\section{Results}

Table 1 displays the descriptive information for traditional and athletic variables. Within the traditional variables it is important to note all categorical variables had relatively equal distributions for each category. For example, the size of the

Table 1 Descriptive Information for Traditional and Athletic Variables

\begin{tabular}{lcccc}
\hline \multicolumn{1}{c}{ Variable } & N & \% & M & SD \\
\hline Traditional & 352 & 52.2 & & \\
Males & 322 & 47.8 & & \\
Females & 513 & 76.1 & & \\
Caucasian & 120 & 17.8 & & \\
African American & 41 & 6.1 & \\
Other Race & 240 & 35.6 & \\
Distance (0-100 miles) & 205 & 30.4 & \\
Distance (101-250 miles) & 229 & 34 & \\
Distance (over 250 miles) & 553 & 82 & \\
Has Major & 121 & 18 & \\
No Major (undecided) & 655 & & 21.7 \\
Standardized Test Scores & 654 & & 3.1 \\
High School GPA & 518 & & 32.1 & \\
High School Rank & 135 & 26.1 & \\
High School Size (1-200 students) & 196 & 37.8 & \\
High School Size (201-400 students) & 187 & 36.1 & & \\
High School Size (over 400 students) & & & \\
Athletic & 204 & 30.3 & \\
Sport-Revenue & 470 & 69.7 & \\
Sport-Non-Revenue & 92 & 13.6 & \\
Coaching Change & 582 & 86.4 & \\
No Coaching Change & 354 & 52.5 & \\
Low Playing Time & 87 & 12.9 & \\
Medium Playing Time & 233 & 34.6 & \\
High Playing Time & 674 & & \\
Team Winning Percentage & & & \\
\hline
\end{tabular}

Note. High School Rank is presented as a \% indicating the average student-athlete in this sample finished in the top $32.1 \%$ of their class. Team Winning Percentage is presented as a \% indicating all student-athletes won $48 \%$ of their total contests. 


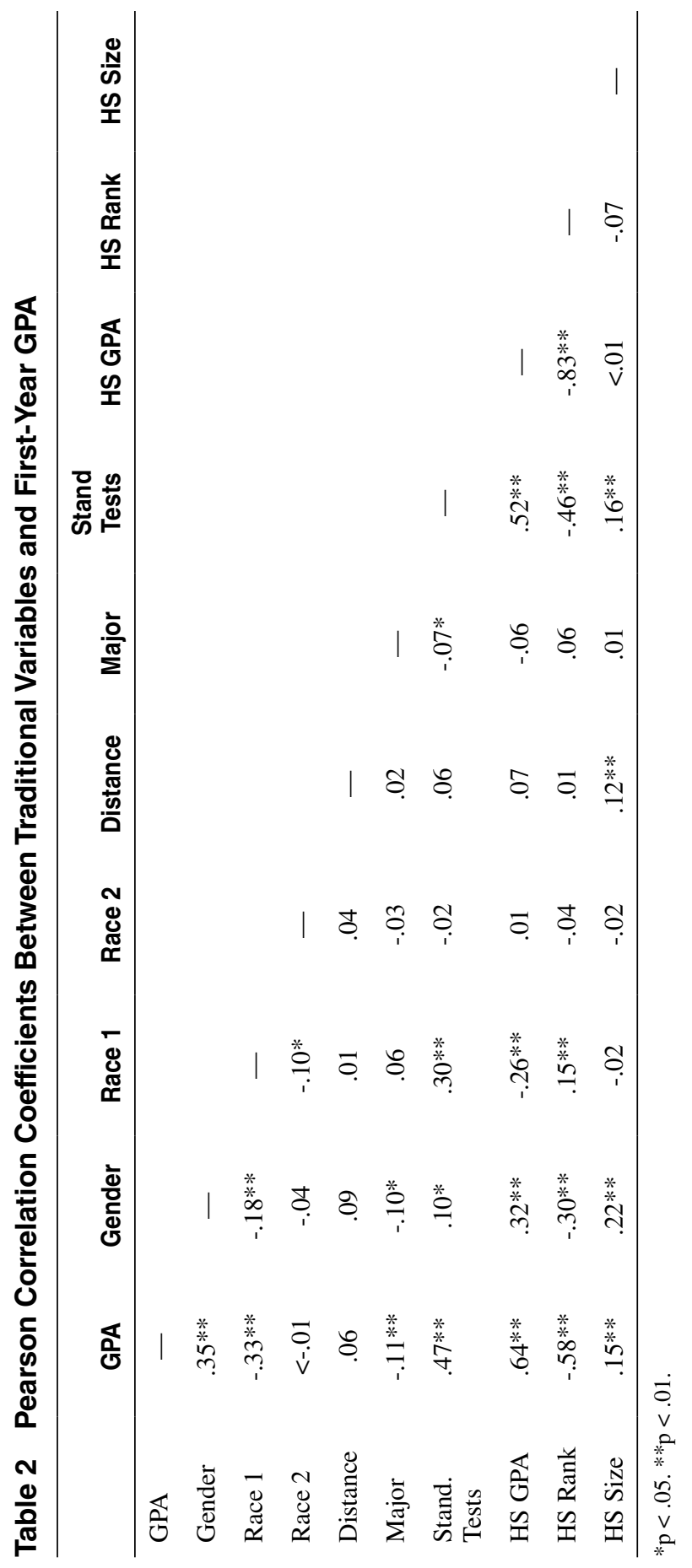


high school graduating classes was divided into small, medium, and large with students totaling 135,196 , and 187 respectively. It is also important to note gender distribution was nearly equal (352 male, 322 female), but race was dominated by Caucasians $(76 \%)$.

Table 2 displays the Pearson Correlation coefficients for the traditional variables. All traditional variables except race 2 (Caucasian vs. other races) and distance from home were significantly correlated to first-year GPA. The most powerful relationships with first-year GPA came from high school GPA $(r=.64)$, high school rank $(r=-.58)$, and standardized test scores $(r=.47)$. It is also important to note the strong correlation between high school GPA and high school rank $(r=-.83)$, which confirms most high school ranking systems rely on GPA.

Table 3 displays the Pearson Correlations between the athletic variables and first-year GPA. Two of the four variables were significantly correlated to first-year GPA at the $p<.01$ level. Type of sport $(r=.33)$ demonstrated the most powerful correlation, followed by playing time $(r=.15)$ Coaching change and team winning percentage were not correlated with first-year GPA. One particularly interesting correlation occurred between distance from home and playing time $(r=.14, p<$ $.01)$. This relationship confirms that student-athletes who attend far from their homes are more likely to have a higher amount of playing time in their first year than student-athletes who came from closer to the university.

\section{Table 3 Pearson Correlation Coefficients Between Athletic Variables and First-Year GPA}

\begin{tabular}{lccccc}
\hline & GPA & Sport & $\begin{array}{c}\text { Coach } \\
\text { Change }\end{array}$ & $\begin{array}{c}\text { Playing } \\
\text { Time }\end{array}$ & Win \% \\
\hline GPA & - & & & & \\
Sport & $33^{* *}$ & - & & & \\
Coach Change & -.06 & $.11 * *$ & - & & \\
Playing Time - & $.15^{* *}$ & $.28^{* *}$ & .07 & - & \\
Win \% & .04 & .03 & $-.26^{* *}$ & $-.08^{*}$ & - \\
\hline
\end{tabular}

$* \mathrm{p}<.05 . * * \mathrm{p}<.01$.

Table 4 displays the summary of the least squares linear regression for the traditional and athletic variables. Of particular note is the dramatic level of significance for traditional variables. Six out of nine traditional variables aided in predicting first-year GPA. Despite the correlation of two athletic variables, none of the athletic variables aided in predicting first-year GPA.

As an overall predictive model, the least squares linear regression analysis was powerful at predicting overall GPA, $F(13)=36.23, p<.01$. Traditional variables accounted for a significant amount of overall GPA variability, $R^{2}=.49, F(10,485)$ $=57.81, p<.01$. Nontraditional variables, however, did not demonstrate significant overall GPA variability, $R^{2}=.50, F(3,480)=1.40, p>.05$. 
Table 4 Summary of Least Squares Regression for Variables Predicting Overall GPA

\begin{tabular}{lccccc}
\hline Variable & $\boldsymbol{B}$ & $\begin{array}{c}\text { Std. } \\
\text { Error }\end{array}$ & Beta & $\boldsymbol{t}$ & sig \\
\hline Traditional & & & & & \\
$\quad$ Gender & .16 & .05 & .13 & 3.21 & $<.01^{*}$ \\
Race 1 & -.26 & .06 & -.16 & -4.17 & $<.01^{* *}$ \\
Race 2 & -.06 & .09 & -.02 & -.64 & .52 \\
Distance & .01 & .03 & .01 & .34 & .74 \\
Major & -.08 & .05 & -.05 & -1.63 & .10 \\
Stand. Tests & .03 & .01 & .16 & 3.88 & $<.01^{* *}$ \\
HS GPA & .41 & .07 & .36 & 5.53 & $<.01^{* *}$ \\
HS Rank & $<-.01$ & $<.01$ & -.15 & -2.40 & $.02^{*}$ \\
HS Size & $<.01$ & $<.01$ & .08 & 2.16 & $.03^{*}$ \\
Athletic & & & & & \\
Sport & -.07 & .06 & -.05 & -1.14 & .26 \\
Coach Change & -.01 & .06 & -.01 & -.22 & .83 \\
Playing Time & .04 & .02 & .06 & 1.66 & .10 \\
Win \% & $<.01$ & $<.01$ & .04 & 1.01 & .31 \\
\hline
\end{tabular}

$* \mathrm{p}<.05 . * * \mathrm{p}<.01$.

\section{Discussion}

\section{Traditional Variables}

The first traditional variable examined, gender, is a variable that has consistently demonstrated a relationship with academic performance. It is well-documented that females, and female student-athletes in particular, outperform their male counterparts in nearly all academic measures (Babington, 1997; Betz \& Fitzgerald, 1987; Durand, 1999; Foltz, 1992; Hosick, 2009; Kane et al., 2008; Mayo, 1982; NCAA Research Staff, 2008; Purdy et al., 1982; Rosser, 1989). The current study confirmed gender as a powerful variable to determine first-year GPA for student-athletes.

The Pearson correlation coefficient between gender and first-year GPA was .35 , and significant at the $p<.01$ level. This result demonstrates a moderately strong relationship between gender and first-year GPA. The ordinary least squares regression analysis revealed gender significantly contributed to the prediction of first-year GPA $(B=.16, p<.05)$. The $B$ value of .16 suggests if all other variables were held constant, females would have a GPA .16 higher than males. These results are consistent with the previous literature indicating female student-athlete GPA, high school measures, standardized test scores, graduation rates, and academic motivation are higher than for males (Melendez, 2006).

Determining females had a higher first-year GPA, and gender significantly aids in predicting first-year GPA, is much easier than establishing why gender is so pow- 
erful. The notion that female student-athletes have a lower level of athletic identity (Melendez, 2006), are more connected to responsibility and care (Chodorow, 1978; Gilligan, 1982), or have a greater investment in social capital (Coleman, 1988) could all be plausible explanations. The answer most likely lies in a combination of these theories. The functional importance of the current research, however, is the application of this information.

If coaches, administrators, and faculty understand gender is a significant variable that predicts first-year GPA, they can make informed programming decisions about resources, curriculum, and academic support. For example, if there are limited academic resources available to an incoming class of first-year student-athletes, it may be reasonable to assume males would need more of these resources than females. It could be expected then, to earn a comparable GPA with females, males on average would see more tutors, have more academic interventions, and be more involved in regulated study activities. However, this type of programming decision may be unrealistic given gender equity guidelines within college athletics.

Race was the second traditional variable examined in this study. Like gender, race is a common variable used in a variety of research. Because race was divided into three categories (Caucasian, African American, and other), and because Caucasians dominated the sample $(n=513)$, the researcher created a system to code the race variable into two categories. The first category, race 1, is a comparison between Caucasian student-athletes and African American student-athletes $(n=$ 120 ). The second category, race 2 , is a comparison of Caucasian student-athletes and student-athletes from other races $(n=41)$. Other races were defined as any race other than Caucasian or African American.

The results revealed race 1 was both significantly correlated to first-year GPA $(r=-.33, p<.01)$, and significantly contributed to predicting first-year GPA $(B=$ $-.26, p<.01)$. In fact, a $B$ value of -.26 indicates African American student-athletes would have a first-year GPA .26 lower than Caucasian student-athletes if all other variables were held constant. These results are not surprising considering research investigating race has consistently found African American students perform at lower academic levels than their Caucasian counterparts (Babington, 1997; Chee et al., 2005; Institute of Diversity and Ethics in Sport, 2006; Kane et al., 2008; Killeya, 2001; Sedlacek \& Adams-Gaston, 1992; Sellers, 1992; Shapiro, 1984; Siegel, 1994; Walter, et al., 1987; Waugh, Micceri, \& Takalkar, 1994).

The reasons for lower African American first-year GPAs may include the desire for equal opportunity and upward mobility while minimizing academic pursuits (Siegel, 1994), a perception of fewer opportunities to gain social and economic success (Edwards, 1986), an over-developed athletic identity (Ashe, 1977; Melendez, 2006), or modern-day racism (Kihl, Richardson, \& Campisi, 2008). Like gender, the reason for a difference in GPA is probably explained by a combination of theories. Also similar to gender, the contribution of this research is the functional use of such information. Allocating proper resources, understanding the unique struggles faced by the African American student-athlete, and acknowledging the difference between Caucasian and African American students upon entering college could aid the coach or administrator in proper planning for the challenges African American student-athletes face. Like gender, understanding the difference between races could then aid in the academic planning and resource allocation for this particular student-athlete sub group. 
Race 2, the difference between Caucasian and other races, was not correlated with, or significant in predicting first-year GPA. This variable was the only traditional variable not significant in any way. Perhaps the sample of other races was too small $(n=41)$, or the diversity of the sample was too mundane to differ much from the Caucasian sample. Or, perhaps other races beyond African Americans do not significantly differ from Caucasian student-athletes with regard to first-year GPA. The results of this study suggest other races perform similarly to Caucasians with regard to first-year GPA.

Distance from home was the third traditional variable investigated, and was neither significantly correlated to first-year GPA, nor significant in predicting first-year GPA. Therefore, the distance a student-athlete attends college from their hometown is not a factor in determining first-year GPA. This finding, although not statistically significant, is valuable because distance from home is a consistent reason for college choice (Briggs, 2006; Cunningham, 1997; Cunningham \& Fickes, 2000; Higher Education Research Institute, 2008; Jonas \& Popovics, 1990; Lam, 1984; Martin, 1996; Mooney, Sherman, \& Lo Presto, 1991; Rajapaksa \& Dundes, 2003). Furthermore, given the established link between distance from home and homesickness (Fisher, 1989), one might inherently assume the farther from home, the more homesick one may become, ultimately lowering one's GPA. However, this is not the case often enough to be related to GPA for student-athletes.

From a practical standpoint, coaches and administrators should understand the farther a particular student-athlete is from their hometown, the lower their ability to connect with their previous social network. This fact, however, does not appear to impact student-athlete academic performance, and gives credence to the importance of an athletic team culture where teammates become a critical social network (Carron \& Hausenblas, 1998). It is also important to note that although distance from home is not related to first-year GPA, it does appear to be related to retention into the second year of college (Johnson, 2010), which has implications for APR scores.

The fourth traditional variable under investigation was major. For the purposes of this study, major was divided into two categories. The first category was students who declared a major upon entering college. The second was students who were undecided about a major upon entering college. Results revealed major was significantly correlated to first-year GPA $(r=-.11, p<.01)$, but did not significantly aid in predicting first-year GPA.

These results were somewhat expected considering the literature regarding the impact of being undecided is inconsistent. On one hand, first-year GPA is correlated with choosing a major. This result suggests student-athletes who choose a major upon entering college have a higher first-year GPA than those student-athletes who are undecided. These findings support contentions by Cooney (2000), Coperthwaite and Knight (1995), Gordon and Steele (2003), Roese and Summerville (2005), St. John (2000), and St. John et al., (2004) who suggested choosing a major is an extremely important decision which represents a serious academic commitment. Such a commitment may be representative of the type of student who would be more engaged in their academic endeavors. In addition, such a student would likely have a higher GPA than a student who did not take this decision seriously. These results do not suggest undecided students cannot take their educational choices seriously, but on average, it appears student-athletes who commit to a major upon entering college perform significantly better than those who do not. 
On the other hand, despite the correlation, major did not aid in significantly predicting first-year GPA. This result supports findings from Knight (1994) and Kroc et al. (1997) who suggested being undecided did not a make a difference in students' path to graduation, and majors may be "bureaucratic, and administrative structures that put arbitrary boundaries on disciplines and restrict creative ways of conceptualizing academic pathways" (Schein \& Laff, 1997, p. 42). Considering the correlation, these arguments are at least partly unsubstantiated, but seem to have some credibility when one considers the impact of major was not powerful enough to be a significant predictor of first-year GPA when combined with other variables. From a practical standpoint, it would be of use to note which student-athletes choose a major, and which do not. This observation may help coaches and administrators evaluate the academic goals and level of academic commitment for each student.

Standardized test scores was the fifth traditional variable investigated. More specifically, the SAT and ACT were evaluated. For the purposes of this study, SAT scores were converted to ACT composite scores using a concordance table (American College Testing, 2009). This conversion allowed the researcher to have a consistent scoring format for both the SAT and ACT. Results demonstrated standardized tests were both significantly correlated $(r=.47, p<.01)$ and significantly contributed to predicting first-year GPA $(B=.03, p<.01)$. In practical terms, these results predict for every point higher a student-athlete scores on standardized tests (ACT composite scale), they can expect a .03 increase to their first-year GPA, assuming all other variables are held constant.

Although the reliability and validity of standardized tests have been debated for quite some time (Babington, 1997; Baumann \& Henschen, 1986; Cantrell, 1999; Hoffman, 1961; Worthen \& Spandel, 1991; Young \& Kobrin, 2001), this research found standardized tests are a useful tool to help predict student-athlete GPA after the first year of college. In fact, the results nearly mirrored the findings by Sacks (1997) who found $16 \%$ of the variation in freshman grades can be predicted using the SAT. Furthermore, this study confirmed the supposition held by Ayers v. Fordice (1995), Bridgeman and Wendler (1989), Burton and Ramist (2001), and Sacks (1997) who suggested standardized tests are valuable to help predict academic performance, but work best when used in conjunction with other predictor variables.

The practical value of this result is evident. Admissions departments, coaches, administrators, and academic support personnel should use the scores from these tests to assist in decisions about recruiting, admissions, and academic performance. Establishing relative cut-off points, or sliding scale measures, are common practices when utilizing standardized test scores. Based on the results of this research, standardized test scores should continue to be used in conjunction with other valuable predictive measures, such as high school GPA.

High School GPA was the sixth traditional variable, and first high school variable evaluated in this research. Prior research with student-athletes has shown high school GPA is a particularly strong predictor of college GPA for student-athletes (Allen, 1986; Baumann \& Henschen, 1986; Lang et al., 1988; Nettles, 1984; Walter et al., 1987). The results of this study confirmed these findings.

High school GPA was both significantly correlated to first-year GPA ( $r=.64$, $p<.01)$, and significantly contributed to predicting first-year GPA $(B=.41, p<$ .01). In addition, high school GPA had a particularly strong relationship to the other predictors in the model $(\beta=.36)$, demonstrating powerful predictive quality. In 
fact, if all other variables were held constant, one would expect first-year college GPA to increase by .41 for every point of improvement in high school GPA. This result indicates high school GPA is the most powerful predictor of first-year GPA when compared with all other predictor variables examined in this study.

The logic relating high school GPA to first-year college GPA is simple. One can assume the academic skills and behaviors used to obtain a high school GPA will continue throughout college, thus producing a similar GPA. Such knowledge can aid coaches and administrators in a prescreening process to assess how individual student-athletes, or entire incoming classes of student-athletes, are likely to perform. This process can also aid in identifying at-risk student-athletes, aid in admission decisions, or assist advisors when helping students choose majors or individual classes. Therefore, high school GPA is a valuable predictive tool that should continue to be used if available to coaches and administrators.

High school class rank was the seventh traditional variable, and second high school variable examined in this study. High school rank referred to the number assigned to students resulting in a ranking relative to others in their high school class. The ranking number assigned to students is usually based on some criteria (e.g., GPA) that place students in order from greatest to least.

Like high school GPA, high school rank was both significantly correlated to first-year GPA $(r=-.58, p<.01)$ and significantly contributed to the prediction model $(B=<-.01, p<.05)$. Therefore, the higher the rank, the higher the first-year college GPA. More specifically, if all other variables were held constant, each increase of 10 percentile points of class rank would improve first-year GPA by .04. The similarity between high school GPA and high school class rank is easily understood when one realizes class rank is usually a result of one's high school GPA (Murphy, 1971). This powerful relationship was confirmed by the current study as demonstrated by the strong correlation between the two variables $(r=-.83, p<.01)$. In other words, when a student has a high GPA, they tend to have a high class rank.

The findings for class rank are consistent with the findings from Cohn et al., (2004), Dittmar (1977), Hengstler and Reichard (1980), Houston (1980, 1983), Ruban and Nora (2002), Schwartz and Wilber (1981), and Slack and Porter (1980) who suggested high school class rank is important in predicting college academic performance. This research does not support the contentions by Murphy (1971) and Lang (2007) who suggested class rank is an inappropriate measure to predict academic success, or make academic decisions. Used in conjunction with other measures, high school class rank does significantly add to the accuracy of predicting first-year GPA for student-athletes.

In much the same way high school GPA could be used to prescreen potential student-athletes, high school rank could also be used. Identifying percentile or cutoff levels, particularly in conjunction with class size, would help identify incoming student-athletes who might achieve at differing academic levels. It is also important to note high school rank was significantly correlated $(p<.01)$ with five of the eight other traditional variables. These results support the contention of Ashbaugh and Thompson (1993) that encouraged the use of high school rank only while considering other academic variables such as class size and quality of high school.

High school size was the final traditional investigated. The logic for the use of class size to predict first-year GPA and retention, besides its connection to class rank, is straightforward. Larger schools often provide more resources, more diversity, 
and more educational and extracurricular opportunities (Ashbaugh \& Thompson, 1993; Geffert \& Christensen, 1998; McDaniel \& Graham, 1999). These additional opportunities are thought to produce a more prepared college freshman.

The results of this study confirmed high school size is significantly correlated to first-year GPA $(r=.15, p<.01)$, and significantly contributed to predicting firstyear GPA $(B=<.01, p<.05)$. Therefore, the larger the high school graduating class, the higher the first-year GPA. Specifically, the results predict for every increase of 100 students in a graduating high school class, one would expect an increase of .02 in first-year GPA of student-athletes, assuming all other variables were held constant. Considering the findings by Geffert and Christensen (1998), as well as Ashbaugh and Thompson (1993), who emphasized the importance of high school size in relationship to available academic resources, it is not a surprise class size is an important factor in predicting first-year college GPA.

Like the other significant traditional variables, utilizing information about high school class size can assist admissions counselors, coaches, and administrators in prescreening student-athletes. Identifying students from larger high schools, particularly those with ample resources, can aid in predicting first-year GPA. Although these results do not condemn student-athletes from small high schools to a low first-year GPA, it is reasonable to assume that on average a student from a larger high school will be more academically prepared than a student from a small high school with limited resources, thus producing a higher first-year GPA.

\section{Athletic Variables}

Sport was the first athletic variable examined. Results from the Pearson correlations $(r=.33, p<.01)$ indicate revenue sports had a significantly lower first-year GPA than nonrevenue sports. This result is to be expected given the documented discrepancies between the academic performance of revenue and nonrevenue sports (Academic Progress Rate, 2009; Christianson, 2009; Eitzen \& Purdy, 1986; Kane et al., 2008; Kihl et al., 2008; Lang et al., 1988; Mayo, 1982; NCAA Research Staff, 2009; Riemer, Beal, \& Schroeder, 2000; Shapiro, 1984; Young \& Sowa, 1992).

Using the same logic, one might expect sport to be a sound predictor of GPA. This was not the case despite having the strongest correlation of all athletic variables. It appears the traditional variables that contributed to predicting first-year GPA were powerful enough to overshadow sport from a prediction equation. When this information is used practically, one can assume revenue sports would require more academic attention than nonrevenue sports to acquire the same GPA. However, predicting GPA would be best served by using traditional variables.

Coaching change was the second athletic variable, and fourth nontraditional variable examined in this study. Coaching change was defined as any change in head coach during the first year of college. Prior research indicates coaches have an influential role in developing the social, psychological, and developmental growth of student-athletes (Amorose, 2003; Baldwin, 1999; Field, 1991; Gagne, Ryan, \& Bargmann, 2003; Giacobbi et al., 2002; Parsh, 2007). Such research may lead one to conclude a coaching change might negatively impact the academic performance of student-athletes.

Results from this study revealed coaching change had no significant correlation, or significant contribution to predicting first-year GPA. Given the supposed impact 
college coaches have on student-athletes, this result was unanticipated. It appears first-year GPA is not impacted by a head coaching change. However, there may be some plausible explanations why this variable proved insignificant.

It is possible the operational definition used in this study could not capture the true impact a college coach has on their student-athletes. For example, if a college coach was removed at the beginning of the academic year, the entire first year of college will have passed before the first-year GPA is calculated. During that time it is possible student-athletes recover from the loss of their coach, or make an equally meaningful connection with their new coach. Likewise, if a student-athlete loses their coach at the end of their first college year, the majority of their first-year GPA may already be established. It is also possible the status of the athlete/coach relationship for coaches who leave their position versus coaches that remain, are different. Perhaps the relationships between coaches who leave their teams and student-athletes are not as strong as those relationships with established coaches. This weakened relationship may be a partial explanation indicating why coaches leave or are terminated. This study did not attempt to ascertain specifically when or why coaches left their position, or what type of individual relationships existed between coaches who left versus coaches who were retained.

Playing time was the third athletic variable, examined. Similar to the variable of sport, the results of this study revealed playing time was significantly correlated with first-semester GPA ( $r=.15, p<.01)$, but did not significantly aid in predicting first-year GPA. The results of the correlation statistic indicate the lower the playing time, the lower the first-year GPA. This result is not a surprise considering the majority of Division I college student-athletes were among the best athletes on their high school teams, but may not earn much playing time their first-year of college (Moe, 1994; Murphy, 1991). This lack of playing time appears to impact other aspects of a student's life, including academic pursuits. Such a result is conceivable when one considers the potential impact of playing time on athletic identity, motivation, and enjoyment (Petlichkoff, 1993a, 1993b; Weiss, McAuley, Ebbeck, \& Wiese, 1990).

In much the same way the variable of sport was overshadowed by the powerfulness of traditional variables within the prediction equation, playing time might also have been overshadowed. This may explain why playing time was significantly correlated to first-year GPA, but did not significantly aid in predicting first-year GPA. Although there is a clear link between playing time and first-year GPA, coaches and administrators should be careful to avoid predicting all students with low-playing time will earn a low GPA. This is not the case. In fact, there were many individual student-athletes within this study who achieved high first-year GPAs and low levels of playing time. Most importantly, these results should send a signal to coaches and administrators that for the average first-year student-athlete playing time is related to academic performance, and understanding how this link may impact individual students, in combination with other variables, could aid in the level of academic intervention.

Team winning percentage was the final athletic variable under investigation. Prior research has shown the winningest teams, particularly in revenue sports that reach televised postseason competition, produce relatively low academic outcomes (Amato, Gandar, Tucker \& Zuber, 1996; Christianson, 2004; Hosick, 2009; Hurley, 1993; Institute for Diversity and Ethics in Sport, 2008; NCAA 
Research Staff, 2008; Shapiro, 1984). Such findings continue to reinforce the dumb jock stereotype. However, other findings have concluded team success dramatically impacts freshman admission applications and financial contributions from donors (McCormick \& Tinsley, 1987; Stinson \& Howard, 2008). This evidence insinuates a link between academic success and team athletic success, and begs the question of whether winning in athletics can go hand in hand with academic achievement.

The results of this study indicate team winning percentage is not related to first-year GPA. This finding reveals student-athletes as a whole are able to separate their athletic team performance from their academic responsibilities. In addition, this finding, in conjunction with the results from playing time, suggests team winning percentage impacts student-athletes' first-year GPA less than individual playing time. This notion is consistent with findings from Akker (1995) and Kotlyarenko and Ehrenberg (2000) who found student-athletes' GPAs were similar to nonathletes, and high athletic success can be matched with high academic success. Coaches and administrators can breathe a sigh of relief knowing team athletic success does not impact student-athletes' first-year GPA.

\section{Conclusion}

This study attempted to establish what combination of traditional and athletic variables best predicted GPA of first-year college student-athletes. GPA was chosen as a dependent variable because it is the number generally used to evaluate many decisions in higher education. Among those decisions are academic and athletic eligibility, scholarship funding, and qualification for academic support services. GPA is also a primary component used to calculate the APR, a real time academic measure used by the NCAA to evaluate team academic performance. Therefore, given the many areas impacted by GPA, as well as the development of the APR, reexamining traditional and athletic predictors of GPA was warranted.

The results reinforced the powerfulness of traditional variables to predict college academic performance. It is not a surprise traditional variables are significant predictors of first-year GPA considering the vast use of these variables by college admission departments, as well as the plethora of research indicating college GPA is linked to these variables. In fact, the current study confirmed that $49 \%$ of the total variance in first-year GPA was explained by the traditional variables. This study clearly demonstrated that contemporary coaches and administrators should continue to use traditional variables to make informed decisions about potential GPAs, especially the variables of gender, race, standardized test scores, and high school GPA.

Although traditional variables were found to be the most substantial predictors, two uniquely athletic variables proved to be significantly correlated to first-year GPA. This result suggests individuals invested in student-athlete academic success should be keenly aware that participating in a revenue sport and receiving a low amount of playing time are negatively related to student-athlete GPA. The practical importance of the athletic variables is clear and viable; after utilizing traditional variables to make predictions about first-year GPA, added concern should be placed on any student-athlete involved in a revenue sport and receiving a low amount of playing time. Utilizing these variables unique to student-athletes, in combination 
with traditional predictors of GPA, to create a more comprehensive student-athlete profile can aid coaches and administrators when making decisions about recruiting, academic support, and athletic participation.

\section{References}

Academic Progress Rate. (2009). NCAA Division I 2007-2008 Academic Progress Rate public report. Retrieved from http://web1.ncaa.org/app_data/apr2008/47_2008_apr.pdf

Akker, K.V. (1995). Athletic participation and the academic achievement of athletes. Unpublished master's thesis, Ball State University, Muncie, Indiana.

Allen, W.R. (1986). Gender and campus race differences in Black student academic performance, racial attitudes, and college satisfaction. Atlanta, GA: Southern Education Foundation.

Amato, L., Gandar, J.M., Tucker, I.B., \& Zuber, R.A. (1996). Bowls versus playoffs: The impact on football player graduation rates in the National Collegiate Athletic Association. Economics of Education Review, 15, 187-195.

American College Testing. (2009). National collegiate retention and persistence to degree rates. Retrieved from http://www.act.org/research/policymakers/pdf/retain_2009.pdf

Amorose, A. (2003). Reflected appraisals and perceived importance of significant others' appraisals as predictors of college athletes' self-perceptions of competence. Research Quarterly for Exercise and Sport, 74, 60-71.

Ashbaugh, D.L., \& Thompson, A.F. (1993). Factors distinguishing exceptional performance on the uniform CPA exam. Journal of Education for Business, 68, 334-337.

Ashe, A. (1977, February 6). An open letter to Black parents: Send your children to the libraries. New York Times, p. E5. Ayers v. Fordice, 879 P. 2d 224 (Kan. 1995).

Babington, C.A. (1997). Traditional and non-traditional predictors of academic success of freshmen student athletes at Indiana University. Dissertation Abstracts International, 58(03), 9724511.

Baker, R.W., \& Siryk, B. (1989). SACQ student adaptation to college questionnaire manual. Los Angeles: Western Psychological Services.

Baldwin, B. (1999). The factors that head football coaches at NCAA Division IA Universities use to evaluate a potential athlete during the recruiting process. Unpublished master's thesis, Ball State University, Muncie, Indiana.

Baumann, S., \& Henschen, K. (1986). A cross-validation study of selected performance measures in predicting academic success among collegiate athletes. Sociology of Sport Journal, 3, 366-371.

Betz, N.E., \& Fitzgerald, L.F. (1987). The career psychology of women. San Diego, CA: Academic Press Inc.

Bridgeman, B., \& Wendler, C. (1989). Prediction of grades in college mathematics courses as a component of the placement validity of SAT-Mathematics scores (College Board Re. No. 89-9). Princeton, NJ: Educational Testing Service.

Briggs, S. (2006). An exploratory study of the factors influencing undergraduate student choice: The case of higher education in Scotland. Studies in Higher Education, 31, $705-722$.

Brown, G.T. (2005, February 14). Implementation of penalty structure triggers new terminology, consequences, questions. NCAA News. Retrieved from http: www.ncaa.org/.../ Division+I/APR+101+-+2-14-05+NCAA+News? pageDesign=Printer+Friendly+NC $\mathrm{AA}+\mathrm{News}+\mathrm{And}+\mathrm{Updates}$

Burton, N.W., \& Ramist, L. (2001). Predicting success in college: SAT studies of classes graduating since 1980 (College Board Rep. No. 2001-2). Princeton, NJ: Educational Testing Service. 
Cantrell, C.E. (1999, January). The legal implications of using standardized tests in admissions. Paper presented at the annual meeting of the Southwest Educational Research Association, San Antonio, TX.

Carron, A.V., \& Hausenblas, H.A. (1998). Group dynamics in sport (2nd ed.). Morgantown, WV: Fitness Information Technology.

Chee, K.H., Pino, N.W., \& Smith, W.L. (2005). Gender differences in the academic ethic and academic achievement. College Student Journal, 39, 604-619.

Chodorow, N. (1978). The reproduction of mothering: Psychoanalysis and the sociology of gender. Berkeley, CA: University of California Press.

Christianson, E. (2004, April 29). NCAA board of directors adopts landmark academic reform package. Retrieved from http://www.ncaa.org/wps/ncaa?ContentID=8126

Christianson, E. (2009, May 6). Baseball, basketball, football, improve their grades. Retrieved from http://www.ncaa.org/wps/ncaa?ContentID=49715

Cohn, E., Cohn, S., Balch, D.C., \& Bradley, J., Jr. (2004). Determinants of undergraduate GPAs: SAT scores, high school GPA and high school rank. Economics of Education Review, 23, 577-586.

Coleman, J.S. (1988). Social capital in the creation of human capital. American Journal of Sociology, 94(Suppl.), 95-120.

Cooney, F. (2000). General studies majors at Salt Lake Community College: A secondary analysis of the fall 1999 new student survey. Salt Lake City, UT: Salt Lake Community College, Department of Administrative Services, Office of Planning and Research.

Coperthwaite, C.A., \& Knight, W.E. (1995, May). Student input, student involvement, and college environment factors impacting the choice of academic major. Paper presented at the annual meeting of the Association for Institutional Research, Boston, MA.

Cunningham, S. (1997). Non-matriculant survey report, fall 1995. Williamsport, PA: Pennsylvania College of Technology, Strategic Planning and Research.

Cunningham, S., \& Fickes, P. (2000). Non-matriculant survey report, 1998. Williamsport, PA: Pennsylvania College of Technology, Strategic Planning and Research.

Dittmar, N.J. (1977). A comparative investigation of the predictive validity of admissions criteria for Anglos, Blacks, and Mexican-Americans. Dissertation Abstracts International, 38(5), 2660A.

Durand, J. (1999). Comparative graduation rates and grade point averages among regular admit, non-competitive admit, and admission exception student-athletes of the University of North Carolina at Chapel Hill. Unpublished master's thesis, University of North Carolina, Chapel Hill, NC.

Edwards, H. (1986). The collegiate athletic arms race. In R.A. Lapchick (Ed.), Fractured focus (pp. 21-62). Lexington, MA: Lexington Books.

Eitzen, D.S., \& Purdy, D.A. (1986). The academic preparation and achievement of Black and White collegiate athletes. Journal of Sport and Social Issues, 10, 15-29.

Field, R.W. (1991). Coach as a role model - what are his salient roles and how do others perceive them? Track Technique, 117, 3730-3733.

Fisher, S. (1989). Homesickness, cognition, and health. Hove. East Suxxex, UK: Lawrence Erlbaum Associates.

Foltz, R.A. (1992). Academic achievement of student-athletes. Unpublished master's thesis, Fort Hays Kansas State University, Hays, Kansas.

Gagne, M., Ryan, R.M., \& Bargmann, K. (2003). Autonomy support and need satisfaction in the motivation and well-being of gymnasts. Journal of Applied Sport Psychology, 15, 372-390 .

Geffert, B., \& Christensen, B. (1998). Things they carry: Attitudes toward, opinions about, and knowledge of libraries and research among incoming college students. Reference \& User Quarterly, 37, 279-289. 
Giacobbi, P.R., Roper, E., Whitney, J., \& Butryn, T. (2002). College coaches' views about the development of successful athletes: A descriptive exploratory investigation. Journal of Sport Behavior, 25, 164-180.

Gilligan, C. (1982). In a different voice: Psychological theory and women's development. Cambridge, MA: Harvard University Press.

Gordon, V.N., \& Steele, G.E. (2003). Undecided first-year students: A 25-year longitudinal study. Journal of the First-Year Experience, 15, 19-38.

Hengstler, D.D., \& Reichard, D.J. (1980, April). Examination of alternative methods and policies for improving the predictive validity of SAT scores and high school rank in freshman admission decisions. Paper presented at the Annual Forum of the Association for Institutional Research, Atlanta, GA.

Higher Education Research Institute. (2008). CIRP freshman survey 2008. Los Angeles, CA: Cooperative Institutional Research Program. Los Angeles: University of California at Los Angeles.

Hoffman, B. (1961). The tyranny of multiple choice tests. Harper's, 222, 37-44.

Hosick, M.B. (2009, May 6). Latest APR jumps three points. NCAA News. Retrieved from http://www.ncaa.org/wps/ncaa?ContentID=49718

Houston, L.N. (1980). Predicting academic achievement among specially admitted Black female undergraduates. Educational and Psychological Measurement, 40, 1189-1195.

Houston, L.N. (1983). The comparative predictive validities of high school rank, the Ammons Quick Test, and two scholastic aptitude test measures for a sample of black female college students. Educational and Psychological Measurement, 43, 1123-1126.

Hurley, M.E. (1993). The role conflict and academic performance of college student-athletes (Doctoral dissertation, University of Miami, Florida, 1993). Dissertation Abstracts International, 54, 2067.

Institute for Diversity and Ethics in Sport. (2008). Keeping score when it counts: Assessing the 2008-2009 bowl-bound college football teams-academic performance improves but race still matters. Retrieved from http://web.bus.ucf.edu/documents/sport/keeping_score_ when_it_counts_assessing_the_200809_bowlbound_college_football_teams_rev2.pdf

Institute for Diversity and Ethics in Sport. (2009). Keeping score when it counts: Sweet 16 men's and women's teams a look at their academic success. Retrieved from http://web. bus.ucf.edu/documents/sport/2009_menwomen_sweet_16.pdf

Johnson, J.E. (2010). Predicting first-year grade point average and retention of studentathletes using demographic, academic, and athletic variables (Unpublished doctoral dissertation). Ball State University, Muncie, IN.

Jonas, P. M., \& Popovics, A. J. (1990). Students' perceptions of an independent college. Cardinal Stritch, WI; Cardinal Stritch College. Retrieved from ERIC database. (ED327104)

Kane, M.J., Leo, P., \& Holleran, L.K. (2008). Issues related to academic support and performance of Division I student-athletes: A case study at the University of Minnesota. Journal of Intercollegiate Sports, 1, 98-130.

Kauss, D. (1978). An investigation of psychological states related to the psycho-emotional readying procedures of competitive athletes. International Journal of Sport Psychology, 9, 134-145.

Kihl, L.A., Richardson, T., \& Campisi, C. (2008). Toward a grounded theory of studentathlete suffering and dealing with academic corruption. Journal of Sport Management, 22, 273-302.

Killeya, L.A. (2001). Idiosyncratic role-elaboration, academic performance, and adjustment among African-American and European-American male college student-athletes. College Student Journal, 35, 87-96.

Knight, W.E. (1994, May). Why the five-year (or longer) bachelors degree?: An exploratory study of time to degree attainment. Paper presented at the annual forum of the Association for Institutional Research, New Orleans, LA. 
Kotlyarenko, D., \& Ehrenberg, R.G. (2000). Ivy League athletic performance: Do brains win? Journal of Sports Economics, 1, 139-150.

Kroc, R., Howard, R., Hull, P., \& Woodard, D. (1997, May). Graduation rates: Do students' academic program choices make a difference? Paper presented at the annual forum of the Association for Institutional Research, Orlando, FL.

Lam, Y.L.J. (1984). Predicting dropouts of university freshmen: A logit regression analysis. Journal of Educational Administration, 22, 74-82.

Lang, D.M. (2007). Class rank, GPA, and valedictorians: How high schools rank students. American Secondary Education, 35(2), 36-48.

Lang, G., Dunham, R.G., \& Alpert, G.P. (1988). Factors related to the academic success and failure of college football players: The case of the mental dropout. Youth \& Society, 20, 209-222.

Martin, C. (1996, May). Institutional research and student recruitment or how do institutions of higher education know what attracts students to their doors? Market research can help. Paper presented at the Annual Forum of the Association of Institutional Research, Albuquerque, NM.

Mayo, A.M. (1982). The relationship between athletic participation and the academic aptitude, achievement and progress of male and female athletes in revenue and non-revenue producing sports at the Ohio State University. Dissertation Abstracts International, 43(5), 137, (8222129).

McCormick, R.E., \& Tinsley, M. (1987). Athletics versus academics - evidence from SAT scores. The Journal of Political Economy, 95, 1103-1116.

McDaniel, C., \& Graham, S.W. (1999, April). Student retention in an historically black institution. Paper presented at the annual meeting of the American Education Research Association, Montreal, Ontario, Canada.

Melendez, M.C. (2006). The influence of athletic participation on the college adjustment of freshmen and sophomore student athletes. Journal of College Student Retention, $8(1), 39-55$.

Moe, P.C. (1994). Earning a varsity letter. A point system based on playing time, performance, effort, and improvement. Scholastic Coach, 63(6), 80-82.

Mooney, S.P., Sherman, M.F., \& Lo Presto, C.T. (1991). Academic locus of control, selfesteem, and perceived distance from home as predictors of college adjustment. Journal of Counseling and Development, 69, 445-448.

Murphy, A. (1991, November 25). Put me in, coach: Playing time is the dream of the Division I walk-on. Bench time is the reality. Sports Illustrated, 75, 134-140, 144, 146.

Murphy, W.F. (1971). Class rank equals measurement and statistics or class rank equals confusion and misunderstanding. The School Counselor, 18, 205-208.

National Collegiate Athletic Association Research Staff. (2008). Seven-year trends in federal graduation rates and graduation success rates at NCAA Division I institutions. Retrieved from http://www.ncaa.org/wps/wcm/connect/53a64b004e0daf00a54bf51a d6fc8b25/2008_d1_7-year_trends.pdf?MOD=AJPERES\&CACHEID=53a64b004e 0daf00a54bf51ad6 fc8b25

National Collegiate Athletic Association Research Staff. (2009). National and sportgroup APR averages, trends and penalties. Retrieved from http://ncaa.org/wps/ $\mathrm{wcm} /$ connect/6851f70 04e0dae9ea486f41ad6fc8b25/Four-Year+APR+Averages. pdf?MOD=AJPERES\& CACHEID=6851f7004e0dae9ea486f41ad6fc8b25

Nettles, M.T. (1984). Racial similarities and differences in the predictors of students' college achievement. Paper presented at the annual meeting of the American Educational Research Association, New Orleans, LA.

Parsh, D. (2007). 8 steps to a coaching philosophy. Coach \& Athletic Director, 76(9), 56-58.

Petlichkoff, L.M. (1993a). Group differences on achievement goal orientations, perceived ability, and level of satisfaction during an athletic season. Pediatric Exercise Science, $5,12-24$. 
Petlichkoff, L.M. (1993b). Relationship of player status and time of season to achievement goals and perceived ability in interscholastic athletes. Pediatric Exercise Science, 5, 242-252.

Purdy, D.A., Eitzen, D.S., \& Hufnagel, R. (1982). Are athletes also students? The educational attainment of college athletes. Social Problems, 29, 439-448.

Rajapaksa, S., \& Dundes, L. (2003). It's a long way home: International student adjustment to living in the United States. Journal of College Student Retention, 4, 15-28.

Ridener, L.R. (1999). Effects of college major on ecological worldviews: A comparison of business, science, and other students [Electronic version]. Journal of Education for Business, 75, 15-21.

Riemer, B.A., Beal, B., \& Schroeder, P. (2000). The influences of peer and university culture on female student athletes' perceptions of career termination, professionalization, and social isolation. Journal of Sport Behavior, 23, 364-379.

Roese, N.J., \& Summerville, A. (2005). What we regret most . . and why. Personality and Social Psychology Bulletin, 31, 1273-1285.

Rosser, P. (1989). The SAT gender gap. Washington, DC: Center for Women's Policy Studies.

Ruban, L., \& Nora, A. (2002, April). Factors impacting the academic status of undergraduate students at four-year institutions. Paper presented at the annual meeting of the American Educational Research Association, New Orleans, LA.

Sacks, P. (1997). Standardized testing: Meritocracy's crooked yardstick. Change, 29, 24-31.

Schein, H.K., \& Laff, N.S. (1997). Working with undecided students: A hands-on strategy. NACADA Journal, 17, 42-48.

Schwartz, S.M., \& Wilbur, F.P. (1981, March). Predicting college achievement using performance in college-level courses taken in high school, SAT scores, and high school rank. Paper presented at the annual meeting of the Eastern Educational Research Association, Philadelphia, PA.

Sedlacek, W.E., \& Adams-Gaston, J. (1992). Predicting the academic success of studentathletes using SAT and noncognitive variables. Journal of Counseling and Development, 70, 724-727.

Sellers, R.M. (1992). Racial differences in the predictors for academic achievement of student-athletes in Division I revenue producing sports. Sociology of Sport Journal, 9, 48-59.

Shapiro, B.J. (1984). Intercollegiate athletic participation and academic achievement: A case study of Michigan State University student-athletes, 1950-1980. Sociology of Sport Journal, 1, 46-51.

Siegel, D. (1994). Higher education and the plight of the Black male athlete. Journal of Sport and Social Issues, 18, 207-223.

Slack, W.V., \& Porter, D. (1980). The Scholastic Aptitude Test: A critical appraisal. Harvard Educational Review, 50, 154-175.

St. John, E. (2000). Do majors matter? Black Issues in Higher Education, 17(4), 20-25.

St. John, E., Hu, S., Simmons, A., Carter, D.F., \& Weber, J. (2004). What difference does a major make? The influence of college major field on persistence by African American and White students. Research in Higher Education, 45, 209-232.

Stinson, J.L., \& Howard, D.R. (2008). Winning does matter: Patterns in private giving to athletic and academic programs at NCAA Division I-AA and I-AAA institutions. Sport Management, 11, 1-20.

Walter, T.L., Smith, D.E.P., Hoey, G., Wilhelm, R., \& Miller, S.D. (1987). Predicting the academic success of college athletes. Research Quarterly for Exercise and Sport, 58, 273-279.

Waugh, G., Micceri, T., \& Takalkar, P. (1994, June). Using ethnicity, SAT/ACT scores, and high school GPA to predict retention and graduation rates. Paper presented at the Florida Association for Institutional Research Conference, Orlando, FL. 
Weiss, M.R., McAuley, E., Ebbeck, V., \& Wiese, D.M. (1990). Self-esteem and causal attributions for children's physical and social competence in sport. Journal of Sport \& Exercise Psychology, 12, 21-36.

Worthen, B.R., \& Spandel, V. (1991). Putting the standardized test debate in perspective. Educational Leadership, 48(5), 65-69.

Young, B.D., \& Sowa, C.J. (1992). Predictors of academic success for Black student athletes. Journal of College Student Development, 33, 318-324.

Young, J.W., \& Kobrin, J.L. (2001). Differential validity differential prediction, and college admission testing: A comprehensive review and analysis (College Board Re. No. 20016). Princeton, NJ: Educational Testing Service.

Zwick, R. (1999). Eliminating standardized tests in college admissions: The new affirmative action? Phi Delta Kappan, 81, 320-324. 